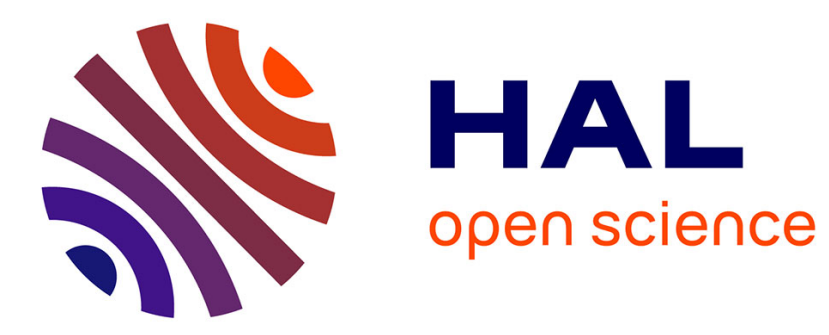

\title{
Using associative networks to represent adopters' beliefs in a multi-agent model of innovation diffusion
}

\author{
Samuel Thiriot, Jean-Daniel Kant
}

\section{To cite this version:}

Samuel Thiriot, Jean-Daniel Kant. Using associative networks to represent adopters' beliefs in a multi-agent model of innovation diffusion. Advances in Complex Systems, 2008, 11 (2), pp.261-272. 10.1142/S0219525908001611 . hal-01169951

\section{HAL Id: hal-01169951 \\ https://hal.science/hal-01169951}

Submitted on 26 Apr 2017

HAL is a multi-disciplinary open access archive for the deposit and dissemination of scientific research documents, whether they are published or not. The documents may come from teaching and research institutions in France or abroad, or from public or private research centers.
L'archive ouverte pluridisciplinaire HAL, est destinée au dépôt et à la diffusion de documents scientifiques de niveau recherche, publiés ou non, émanant des établissements d'enseignement et de recherche français ou étrangers, des laboratoires publics ou privés. 
January $\quad 2008 \quad 17: 5$ WSPC/INSTRUCTION $\quad$ FILE croyances et innovation journal

Advances in Complex Systems

(c) World Scientific Publishing Company

\title{
Using associative networks to represent adopters' beliefs in a multi-agent model of innovation diffusion
}

\author{
SAMUEL THIRIOT \\ Computer Science Laboratory (LIP6) \\ University Pierre et Marie Curie - Paris 6 \\ 104 avenue du Président Kennedy \\ 75016 Paris, France \\ Samuel.Thiriot@lip6.fr \\ JEAN-DANIEL KANT \\ Computer Science Laboratory (LIP6) \\ University Pierre et Marie Curie - Paris 6 \\ 104 avenue du Président Kennedy \\ 75016 Paris, France \\ Jean-Daniel.Kant@lip6.fr \\ Received (received date) \\ Revised (revised date)
}

\begin{abstract}
A lot of agent-based models were built to study diffusion of innovations. In most of these models, beliefs of individuals about the innovation were not represented at all, or in an highly simplified way. In this paper, we argue that representing beliefs could help to tackle problematics identified for diffusion of innovations, like misunderstanding of information, which can lead to diffusion failure, or diffusion of linked inventions. We propose a formalization of beliefs and messages as associative networks. This representation allows to study the social representations of innovations and to validate diffusion models against real data. It could also make models usable to analyze diffusion prior to product launch. Our approach is illustrated by a simulation of $\mathrm{iPod}^{\mathrm{TM}}$ diffusion.
\end{abstract}

Keywords: agent-based modelling; diffusion of innovations; knowledge representation.

\section{Why representing beliefs ?}

Diffusion of innovations is an interdisciplinary field that studies "the spread of new ideas, opinions, or products troughout a society" [19]. Rogers defines diffusion "as the process by which an innovation is communicated through certain channels over time among the members of a social system" [17, p. 11].

Several models were built to study diffusion of innovations, including multiagent based simulations, with different purposes. Explicative models aim to reach a better understanding of how individual interactions make collective dynamics appear. A great part of these models studies the decision/judgment level (adoption, opinion, perceived utility[7], payoff [3], attitude, etc.). For instance, in the threshold 
model (e.g. [6]), social pressure makes individuals influenced by opinions of their neighbours. Several models also include the beliefs level, that is what individuals trust for a given object (one use "belief" rather than "knowledge" because these beliefs can be false or subjective). It is the case of models focused on informational cascades (see [16] for a review) or in the consumat approach [9]. In these models, beliefs are represented as single values or as a vector of values, and rarely aim to be matched against data collected on the field.

Predictive models aim to produce an estimation of the future diffusion rate of an innovation. The well-known model, and the most used in industry, is the Bass aggregative model [4]. It includes parameters for adoption due to media messages, adoption due to interpersonal communication and an index of market potential for the new product. It permits to reproduct the classical S-curve of cumulated adoption.

Despite of the large amount of litterature about diffusion of innovation, there still remain several problems that are not studied. The first lack resides in explicative power. Rogers [17] underlines that models are not able to explain innovation failures (sometimes due to misunderstanding of what innovations are or to incompatibility with beliefs or values). Rogers also remarks that most of the said "innovations" launched in markets are in fact incremental products. In this case people already understand what the innovation is, how it works, so the diffusion becomes quicker. Such processes cannot be modelled without representing beliefs of the population about innovations. The second lack is about predictive power. The Bass model can predict the future adoption rate of an innovation only after its launch, based on the adoption data from innovators and early adopters. But at this time, costs are already engaged (for building the product, for communication, etc.). Obvisouly, the predictive interest of the model is highly lowered. So, firms use less formal methods to test new concepts, like interviews or focus groups, which provide some insights on subjective perception and expectations about the innovation. Here again, it seems that modellers cannot avoid to represent beliefs.

Our main concern is to be able to tackle real-world cases. In this paper we study how a modeller can represent individual beliefs in an agent-based simulation. For such a simulation, we need a model for knowledge representation that is complex enough to be explicative and representative, but also simple enough to make its parameters' settings and data collection possible. We illustrate this approach with the simulation of iPod ${ }^{\mathrm{TM}}$ diffusion using beliefs collected across forums.

\section{Model}

\subsection{Beliefs as associative links}

\subsubsection{Individual Associative Network}

The concept of associative network has been widely used in social sciences and artificial intelligence to model beliefs: bayesian networks, causal networks, social repre- 


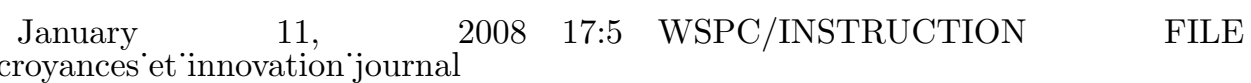

Using associative networks to represent adopters' beliefs in a multi-agent model of innovation diffusion 3

sentations represented as proximity networks, etc. A marketing methodology called the Means-end Chains Theory (MCT) [15] proposes to formalize the perception of products as cognitive chains linking concrete attributes to perceived consequences for the individual and satisfaction of his values. As shown by the MCT, associative networks are relevant to represent the beliefs about products (an example is provided in Figure 1). These chains can be retrieved by semi-directed interviews, surveys or stastistical data analysis. Messages like advertisement or consumer reviews can also be represented as chains [14], as shown in Figure 3.

Associative networks permit to represent several kinds of knowledge. We categorize knowledge as private, concrete or subjective ${ }^{\mathrm{a}}$. The subjective part of information is about the innovation itself, like product attributes (links 2-7) and perceived functional consequences of the product (e.g. 11,13). This kind of information is received or retrieved by individuals through mass medias or interpersonnal communication. The private part of beliefs are about individuals themselves. These beliefs are more stable for an individual accross time [12]. For instance, the belief "speed $\rightarrow$ time saving" is used for all technological innovations. Private beliefs can be heuristics, like "high price $\rightarrow$ high quality". Private beliefs are provided as initial data by the modeller based on the population segmentation. The last kind of beliefs is about abstract judgments and is built by the individual itself based on its local information, as "product adopted by others". This knowledge is represented in agents by simple computational rules held by each agent.

From the modeller viewpoint, concepts in the model are a finite set $\mathcal{C}$, which is created based on data collection or expert hypothesis. Sometimes two or more concepts are incompatible: an agent cannot trust both of them in the same time for the same social object. As in theory of evidence, we define frames of exclusivity called $\Theta^{\mathcal{X}}$, with $\mathcal{X} \subset \mathcal{C}$. Some exemples of frames are: (solid, breakable), (good connectivity, bad connectivity).

Formally, we define knowledge as directed associations between concepts. Mathematically, a belief is a binary relation in $\mathcal{C}^{2} . C_{1} b_{\sigma}^{a, t} C_{2}$ is the conviction held by an agent $a \in \mathcal{A}$ at time $t$ that two concepts $\left(C_{1}\right.$ and $\left.C_{2}\right) \in \mathcal{C}^{2}$ are associated with a given support $\sigma \in \Sigma$. The support represents the confidence of the agent on this belief (more details on support are provided below). In this model, existence of a link represents belief. No link means ignorance. Disbelief is modelled as the belief in the opposite concept. Each individual possesses his own set of beliefs; we name this set an Individual Assocative Network (IAN).

Some concepts are considered as object of interest by the agents $\mathcal{A}$ (agents will speak about them, they want to understand them, they can take decisions about these concepts). We use a psychosocial term [10] to design these objects of common

aThis taxinomy follows the one provided by Audenaert and Steenkamp's studies on means-end chains theory [2], and the discussion in the field of consumer value [8], which concludes that perceived value depends both on the intrisic product properties and on the subjective perception of consumers 
January $\quad 11$

croyances et innovation journal

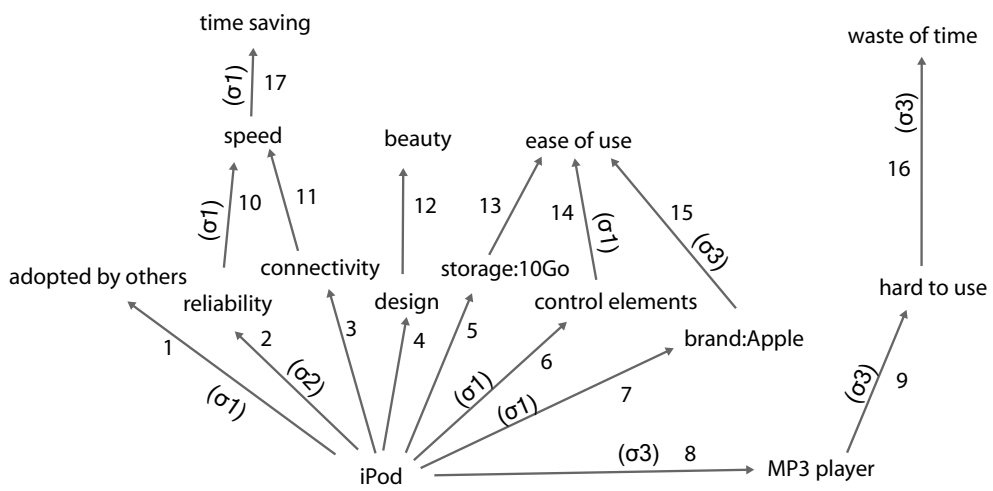

Fig. 1. Exemple of Individual Associative Network (IAN) retrieved by interview for $\operatorname{iPod}^{\mathrm{TM}}$ (study on what people like or dislike for this product). To improve lisibility only useful supports are provided. $\sigma_{1}$ represents the support "personal experience", $\sigma_{2}$ means "indirect experience" and $\sigma_{3}$ "no credibility"

interest: these concepts are social objects $\mathcal{O} \subset \mathcal{C}$. When we model the diffusion of innovations, social objects are innovations. A set of beliefs about a social object $o$ forms the representation $R_{o}^{a, t}$ of this object. This representation is the subgraph rooted in the social object. If a representation is shared between several agents, it becomes a social representation in the social psychology meaning, noted $S R_{o}^{\mathcal{X}, t}$ with $o \in \mathcal{O}, \mathcal{X} \subset A$.

\subsubsection{Beliefs Revision}

Insights about persuasive communication are provided by social psychology [10]. Persuasivness of a communication depends on properties of the source like credibility, expertise, self-interest, structure of argumentation, messages order, etc. No formal model exists to compute the total persuasiveness of a communication based on these parameters. However, several formalisms are available to represent beliefs and their strength, mainly with probabilities or belief functions (see [18] for a comparative review). But, all of these models are normative and lead to results incompatible with observable evidence. They would require us to include quantitative valuation of beliefs (as probabilities or belief masses), which would make the model harder to validate, less representative and harder to manipulate. So, we developped a solution based only on the qualitative properties of beliefs.

The sources of informations are perceived as more or less credible by individuals. Broadly speaking, personal experience is stronger than other advices, themselves stronger than advertisement. We define a set $\Sigma$ that contains several levels of support (in other words: credibility, certainty, revisability, strength). Each source of information is categorized by the agents in one of these levels. Levels are defined operationally to fit observations from the population and the needs of the model. Currently we work with the following levels: no credibility is used for in- 


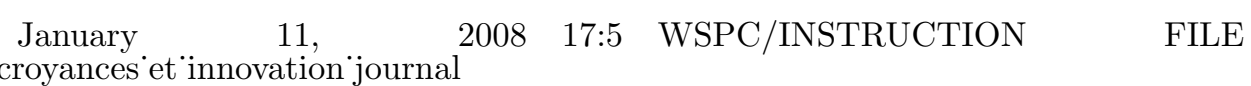

Using associative networks to represent adopters' beliefs in a multi-agent model of innovation diffusion 5

formation from advertisement, plausible is used for advice from someone, indirect experience represents feedback of someone based on its personal experience. Personal experience represents the strongest level for beliefs acquired by the agent direct experience.

\begin{tabular}{|c|c|c|c|c|}
\hline & no credibility & plausible & indirect experience & personal experience \\
\hline no credibility & 0.9 & 0 & 0 & 0 \\
\hline plausible & 1 & 0.9 & 0.01 & 0.001 \\
\hline indirect experience & 1 & 1 & 0.9 & 0.001 \\
\hline personal experience & 1 & 1 & 1 & 0.9 \\
\hline
\end{tabular}

Table 1. probability of revising a belief based on the support level of the previous belief $\sigma_{\text {old }}$ (top) and on the support level of the new information $\sigma_{n e w}$ (left column)

We assume that a stronger source erases the previous advice, because the new source is considered to be more credible. In some cases, however, it is possible for a strong belief (acquired by direct experience) to be modified by new weaklysupported information, because individuals accept to revise old beliefs, comply with social consensus, can be convinced by a good argumentation or another reason. That's why we choose to model belief revision based on probabilities of revision between support categories $p$ (revise $\left.\mid \sigma_{\text {old }}, \sigma_{\text {new }}\right)$. We built this function (Table 1 ) based on qualitative observations. A weak support has a low probability to modify a stronger support. However in long term, this probability becomes higher and higher, leading to invalidate old beliefs. This model is easier to validate than a quantitative representation of strength.

\subsubsection{Retrieving from memory}

We need to be able to retrieve the representation of a social object contained in an IAN. Retrieving a representation is an spreading activation process: start from the social object, then browse all the links connected to this node to build the representation $R_{o}^{a, t}$. We assume an activation propagation inspired by evidence networks: the activation strength of a concept for an object is the strength of the weakest link in the chain that links the social object to this concept. When activation follows a link, activation is filtered by the belief strength. For instance in Figure 1, activation of concept "time saving" for the social object "iPod" is "indirect experience", which is the lowest support in the chain $\left(\sigma_{2}\right)$. If a node receives several levels of activation from its parents, the stronger activation is kept (MAX-activation, which is also an OR logical interpretation). In the example of Figure 1, "ease of use" has a support of "personal experience". As a result, the activated representation contains the beliefs activated and their support.

In the particular case of incompatible beliefs, the activation process only keeps the strongest belief. For instance in Figure 1, the frame of exclusivity $\theta_{\text {complexity }}=$ \{ease of use, hard to use\} forbids both of these concepts to be trusted at the same 


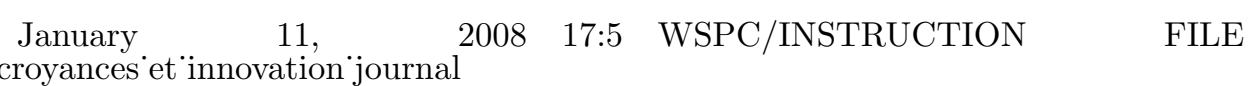

6 Samuel Thiriot and Jean-Daniel Kant

\begin{tabular}{|c|c|c|}
\hline & big audience & small audience \\
\hline interactive topic choice & forums, search on internet & face-to-face \\
\hline static topic & press, advertisement, direct experience & weblogs \\
\hline
\end{tabular}

Table 2. taxinomy of channels

time. The spreading activation process sets a low activation to "hard to use" and an higher to "ease of use", so only the last one will be included in the activated representation.

\subsection{Communication}

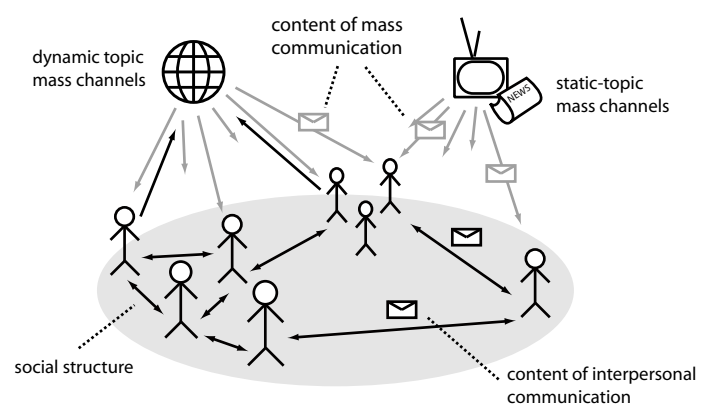

Fig. 2. Communication in a real population

As shown before by the agent-based modelling community, the social structure has a huge impact on the system dynamics (e.g. [20]). A model of communication, that it too simple - like random meeting or cellular automata - doesn't seem adequate. As a consequence, we detail here explicitely the channels that support communication, the structure of messages themselves, and the topics (social objects) agents are talking about.

A channel is a support of communication that transmits information from an information source to an audience. Historically mass media were controlled by firms for persuasive communication, while interpersonal channels were only used for uninterested communication. Today individuals' reviews through specialized websites or forums could challenge traditional mass media, and interpersonal communication begins to be modified by individuals who are paid to propagate positive recommandations. To take this evolution into account, we propose to categorize channels based on their audience size and the determination of topics (Table 2). An unidirectional channel will always have a static topic (because the information source communicates about the object of its choice) while bidirectionnal channels allow interactive choice of topic. Modelling interactive topics implies modelling information research, and not only passive information reception. 

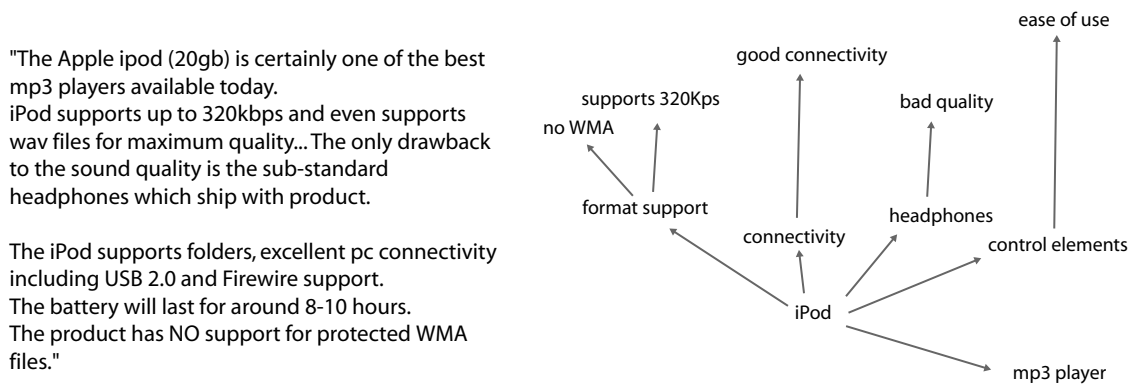

Fig. 3. Transcription of a consumer advice retreived on a website (left) as a TAN (right)

A mass channel is connected to a great number of agents. The agent exposure defines its probability to receive messages through this channel. An interpersonal channel represents the fact that two individuals can exchange information with a given exposure parameter (the probability for the agents to meet). A statictopic channel will only transmit passively messages, so the topic is determined by the information source. An interactive-topic choice channel asks both agents which topics they want to discuss about (the salient social objects set of each agent) and pick up randomly a social object in the union of the two sets.

\subsection{Messages}

Each transmission of information (either from mass media or interpersonal) is a message. A message is intended to transmit information ${ }^{\mathrm{b}}$ about a social object. A message is sent by a sender over a channel; audience will be determined by the channel itself. A communication campaign is composed of several messages broadcasted on channels during a given period.

The content of a message is a transmissible associative network (TAN), which is made of associative links (see Figure 3 for example). A TAN typically embodies only a representation of a single social object. Sometimes - especially in the case of co-branding - the network can include several social objects and their associated representations. A TAN transmitted by an extrinsic information source is provided by the modeller. A TAN from an intrinsic information source is dynamically built by this agent.

\subsection{Agents}

A consumer agent represents a unit of adoption. It embodies a belief base, a list of currently salient social objects and is linked to an agent profile. An agent profile contains the default exposure to mass channels, background knowledge, subjective

\footnotetext{
${ }^{\mathrm{b}}$ This definition of a message is voluntarily simplified to fit the frame of this paper. A message,
} especially an advertisement, also embodies some non-semantical components. 
January $\quad 2008$ 11, $\quad 27: 5$ WSPC/INSTRUCTION FILE croyances et innovation journal

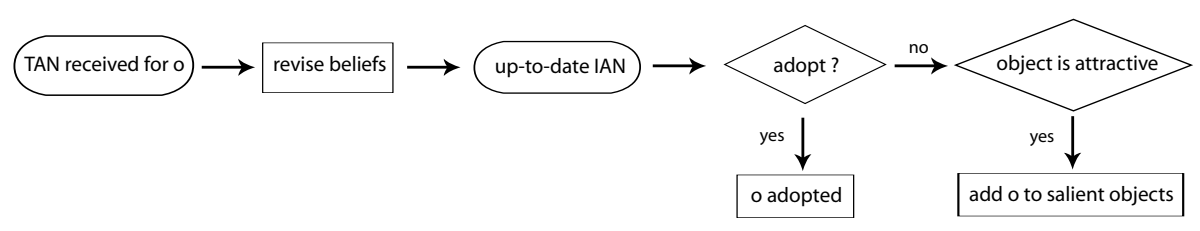

Fig. 4. Exemple of decision process

production of knowledge. It also contains functions to evaluate attractivity and decide adoption. It can also include some rules to create the subjective knowledge based on local information. For instance, the fact that others have adopted a product (belief number 1 in Figure 1) is modelled by a threshold on the observed relashionships that possess the product.

The definition of the agent's behavior is out of the scope of this paper. The modeller can implement whatever models he wants based on the internal representation of beliefs, which provides both beliefs and their strength. Several models exist to describe attitude formation or adoption based on beliefs, as the Theory of Planned Behaviour [1], the Fishbein model or any multi-criteria model.

As an example we currently use the behavior process represented in Figure 4. We designed multicritera functions to compute attractivity and adoption, which take into consideration the support of beliefs.

Based on these three functions, the following process appears, which is compliant with existing models of buying steps or adoption process [17]. (1) first the agent becomes aware of the innovation, and receives prior information. (2) if the information is attractive enough, the agent decides to look for it (3) if the agent thinks it has enough information, it decides to adopt or not (4) using the product, it receives more information by usage and participates to word-of-mouth.

\section{Application to iPod ${ }^{\mathrm{TM}}$}

\subsection{Data collection}

We retreived data from the published means-end chains analysis of iPod ${ }^{\mathrm{TM}}[13]$ and from statistical analysis of reviews provided by consumers on specialized websites. This data is used to determine the content of interpersonal messages and to insert background knowledge into agents. Associative networks permit to represent background knowledge. For instance in Figure 1, the links $(9,16)$ represent fears of late majority about technology: it's hard to use and leads to waste of time.

We identified the following static-topic mass channels: TV advertisement, generalist and specialized press, experience with the product. We set exposure to each media from general statistics published about TV ads exposure, press reading, etc. We used as a social structure a small-world graph (a regular lattice with shortcuts as proposed in [11]). The exposure level to social interactions is retreived from a study [5] about word-of-mouth, which quantifies on average 15 word-of-mouth 
January $\quad 2008 \quad 17: 5$ WSPC/INSTRUCTION $\quad$ FILE

croyances et innovation journal

Using associative networks to represent adopters' beliefs in a multi-agent model of innovation diffusion

episodes per week.

\subsection{Agent profiles}

We adopt the classical segmentation used in diffusion of innovations. Innovators like what is new, fun. They enjoy to spent time to learn how an innovation works. They are able to understand technological terms. They read specialized press nearly ones a week. They are more impulsive than others, and can adopt an innovation as soon as it is available. They easily speak about innovations. They like to be alone to possess new things, and an innovation already possessed by others loose its interest. Early adopters sometimes read specialized press. They like new thinks, they carefully study available information before buying. Individuals from early majority like to be on-trend, with new products. They already have a good knowledge about technology, but like to have feedback from first adopters before buying. Late majority don't cares about the novelty of a product. They focus on the utilitarian aspect, don't like to loose time to learn new techologies. As part of their background knowledge, they believe that technological innovations are hard to use (as represented by beliefs 9,16 in Figure 1). They consider a piece of information as true only if it comes from someone else with direct experience. Laggards have a low exposure to press, and retreive most of their information from interpersonal communication.

\subsection{Simulation}

The model is implemented with the Repast Framework. In this discrete-time simulation, each step represents one week.

Graph 5 shows the output of the model. Awareness starts before adoption due to annoucement information transmitted about iPod ${ }^{\mathrm{TM}}$. Because an announcement is only transmitted in specialized press, mainly innovators and early adopters are aware of the product and can propage word-of-mouth around them. Then the product is launched, with information in generalist press and TV advertisement. All the population becomes aware of the product and can adopt it. Early majority requires indirect information from previous users or independant reviews to adopt. Late majority needs indirect feedback to adopt. The last curve in this figure shows that the diffusion is made quicker if another media (here: internet) permits to retrieve others advices quicker than face-to-face communication; this media is highly efficient because it permits to determine interactively topics and to retrieve credible information.

\subsection{Observations}

How to improve diffusion? In this model advertisement on its own doesn't lead to adoption, but can make the product salient in individual minds and provoque adoption or word-of-mouth. The best idea to make diffusion quicker is to facilitate word-of-mouth, which is required to persuade late majority and laggards to adopt. 


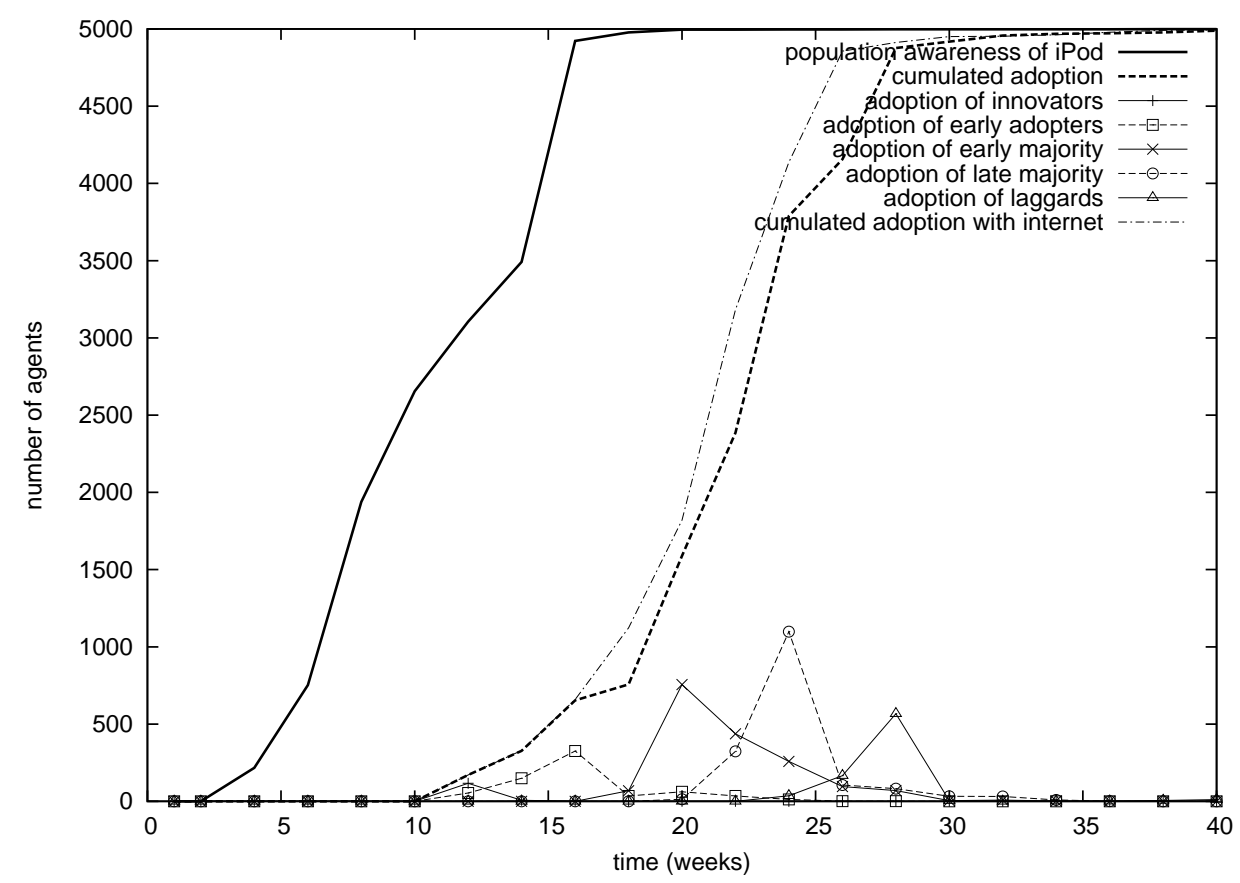

Fig. 5. Simulation of Pod $^{\mathrm{TM}}$ diffusion in a population of 5000 agents

A good timing, and attractive information, is require to stimulate word-of-mouth. If new information is sent when individuals are still looking for information, then this new information will be transmitted quickly through interpersonnal communication. Observability, one of the factors mentionned by Rogers, also facilitates diffusion in this model. In the case of $\mathrm{iPod}^{\mathrm{TM}}$, the white hearspeakers are easily identifiable, and are related to iPod ${ }^{\mathrm{TM}}$ based on advertisement campaigns. So potential adopters are aware of others adoption, leading them to follow this indirect recommandation. The importance of usage value, as in reality, is confirmed, because individuals who use the products are highly credible and can provoque adoption; it is of prime importance that they be satisfied by the product.

Social representations of the innovation appear in the model. In the beginning of diffusion, we can observe collective representations shared by several agents (Figure 6): individuals who have already adopted possess a large amount of information provided by experience, while others only have a representation created from advertisement. Individuals who had no knowledge about mp3 players discover through word-of-mouth what are the criteria for evaluating the innovation. While late majority is initialized with no knowledge about mp3 players, all individuals end with general considerations about autonomy or storage capacity. We also observe examples of incomprehension: an individual who has no knowledge about storage capacity is unable to understand what " $10 \mathrm{~Gb}$ " means, but he will learn it through interper- 

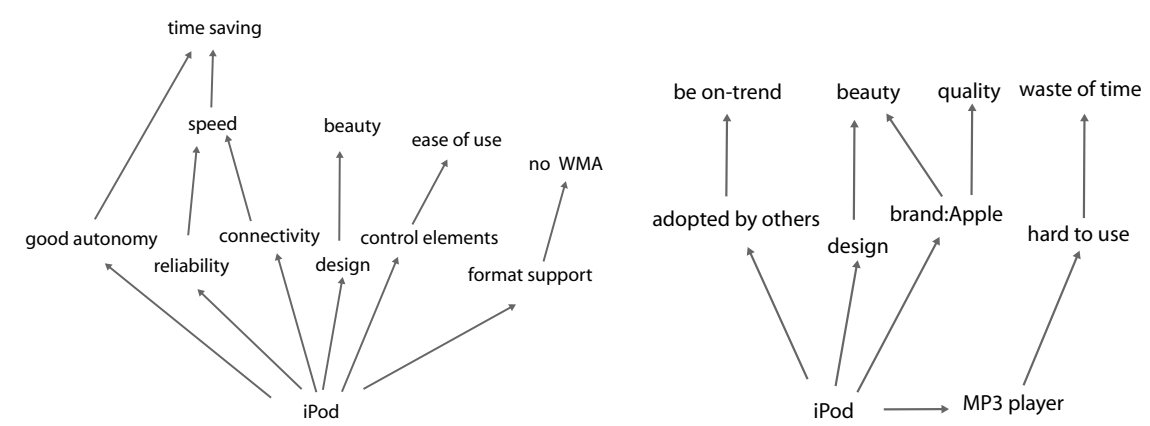

Fig. 6. Example of social representations. The left representation $S R_{i P o d}^{\text {earlyadopters, } 12}$ is shared by first adopters who have already an experience with $\mathrm{iPod}^{\mathrm{TM}}$. The right representation

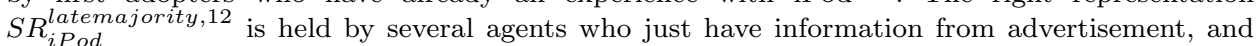
know that $\mathrm{iPod}^{\mathrm{TM}}$ is already widely adopted.

sonal messages or well-designed advertisement (with the slogan "1000 songs in your pocket").

\section{Discussion}

Representing knowledge as associative networks permits to create models which can be tested against real data, and to represent both messages and individual knowledge in a computationnally tractable way. This representation is highly representative and manipulable, even for non-experts. Implicitly it allows to model misunderstanding of information, word-of-mouth or launch of related innovation in a more plausible way - in fact models that were expected by Rogers. Hence we could build models that represent the whole adoption process, from awareness to decision.

When a diffusion model is built to be used as a decision-support system, this approach is obviously more instructive. Through simulation the modeller is able to study the true parameters of diffusion of innovation (those mentionned by Rogers and used by marketers): what is the perception of products ? In what way are consumers aware of a product ? What is the background knowledge of individuals, and will they be able to understand information ? Why does an innovation provoke word-of-mouth ? Used before innovation launch, the model can be parameterized from interviews - for subjective perception of the innovation - and general information- for background knowledge -, giving one an efficient methodology to test possible diffusion cases.

The main limitation of such a model is the state of knowledge about human behavior and social phenomena: no sufficient information is available about the structure of real social networks, what provokes word-of-mouth, etc. Our future work will be focused on the validation of models based on associative networks, including interview protocols and statistical methods. 


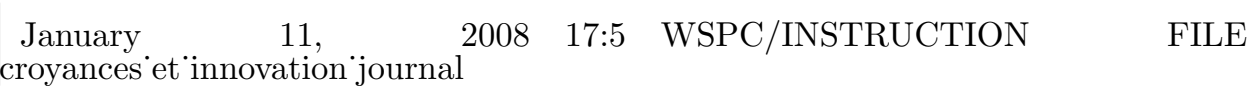

\section{References}

[1] I. Ajzen. The theory of planned behavior. Organizational behavior and Human Decision Processes, 50:179-211, 1991.

[2] A. Audenaert and J. Steenkamp. Agricultural marketing and consumer behavior in a changing world, chapter Means-end chain theory and laddering in agricultural marketing research, pages 217-230. Boston: Kluwer, 1997.

[3] A. Banerjee and D. Fudenberg. Word-of-mouth learning. Games and Economic Behavior, 46:1-22, 2004.

[4] F. M. Bass. A new product growth for model consumer durables. Management Science, 15(5):215-227, January 1969.

[5] W. J. Carl. What's all the buzz about? everyday communication and the relational basis of word-of-mouth and buzz marketing practices. Management Communication Quarterly, 19(4):601-634, 2006.

[6] G. Deffuant, S. Huet, and F. Amblard. An individual-based model of innovation diffusion mixing social value and individual benefit. American Journal of Sociology, 110:1041-1069, 2005.

[7] G. Ellison and D. Fudenberg. Word-of-mouth communication and social learning. The Quarterly Journal of Economics, 110(1):93-125, Feb 1995.

[8] M. B. Holbrook. Consumer Value : A framework for analysis and research, chapter Introduction to consumer value, pages 1-28. Routledge, New York, 1999.

[9] M. A. Janssen and W. Jager. Simulating market dynamics: Interactions between consumer psychology and social networks. Artifical Life, 9:343-356, 2003.

[10] S. Moscovici. Psychologie Sociale. Presses Universitaires de France, 7th edition, 1998.

[11] M. E. J. Newman and D. J. Watts. Renormalization group analysis of the small-world network model. Physics Letters A, 263:341-346, 1999.

[12] A. L. Page, D. N. Cox, C. G. Russell, and P. I. Leppard. Assessing the predictive value of means-end-chain theory: an application to meat product choice by australian middle-aged women. Appetite, 44:151-162, 2005.

[13] A. E. Reppel, I. Szmigin, and T. Gruber. The ipod phenomenon: identifying a market leader's secrets through qualitative marketing research. Journal of Product and Brand Management, 15(4):239-249, 2006.

[14] T. J. Reynolds, C. E. Gengler, and D. J. Howard. A means-end analysis of brand persuasion through advertising. International Journal of Research in Marketing, 12:257266, 1995.

[15] T. J. Reynolds and J. Gutman. Laddering theory, method, analysis, and interpretation. Journal of Advertising Research, pages 11-31, 1988.

[16] J. H. Roberts and J. M. Lattin. New-Product Diffusion Models, chapter Disaggregatelevel Diffusion Models, pages 207-236. Springer, 2000.

[17] E. M. Rogers. Diffusion of Innovations. New York: Free Press, 5th edition, 2003.

[18] P. Smets. Handbook of Defeasible Reasoning and Uncertainty Management Systems, volume 1, chapter Probability, Possibility, Belief: Which and Where ?, pages 1-24. Kluwer, Doordrecht, 1998.

[19] T. Valente. Network Models of the Diffusion of Innovations. Cresskill NJ: Hampton Press, 1995.

[20] T. W. Valente. Network models of the diffusion of information. Hampton Press Inc., Cresskill: NJ, 1995. 